\title{
Piezoelectric devices for energy harvesting in building structures
}

\author{
Ludmila Grigoryeva \\ Kyiv National University of Construction and Architecture, \\ Povitroflotsky avenue 31, Kyiv, Ukraine, 03061 \\ grygorieva.lo@knuba.edu.ua, https://orcid.org/0000-0001-7013-0327
}

Received 02.05.2021, accepted 19.05.2021

https://doi.org/10.32347/tit2141.0102

\section{INTRODUCTION}

Devices that convert vibration energy into electricity and are capable of its accumulation (energy harvesting) are very promising both in mechanical engineering (damping oscillations with the conversion of excess energy into electricity) and in electronics and the environment (systems for energy storage and replenishment). That systems convert extra motion of engineering devises into electrical energy used for their autonomous operation or for power supply of other devices [1]. Another application is portable electronics, where energy storage devices can power or charge mobile phones or other devices. When energy sources are limited, energy harvesting plays an important role in the environment.

Energy harvesting as a separate direction began to develop in the 1990s. Human, bicycle, water flow, low-frequency oscillations in mechanisms, etc. can be used as sources of mechanical energy for the piezoelectric transducer. Usually, due to steady oscillations, piezoelectric elements produce alternating electric current, showing the greatest efficiency at resonant frequencies. Most piezoelectric power sources produce power of the order of milliwatts, which is small enough for system use but sufficient for portable devices. Piezoelectric systems can convert the movement of the human body, such as the movement of legs and arms, shocks and blood pressure to obtain energy from implanted or portable sensors. Piezoelectric elements are built into running and walking roads, shoes, pavement, etc. One of the priority areas of research is the development of autonomous wireless sensors that receive energy from the measured signal, or use other ways to obtain mechanical energy. Their use becomes relevant in atypical tasks - measuring oscillations in hard-to-reach places of rotating mechanisms, seismic sensors and so on. Smart roads can play an important role in electricity generation. The incorporation of piezoelectric material into the road can convert the pressure exerted by moving cars into voltage and current.

\section{STRUCTURE OF ENERGY HARVESTING SYSTEMS}

For energy hurvesting usually are used sensors and motors of cantilever beam structure, consisting of a membrane lower electrode, film, piezoelectric film and the upper electrode (bimorphs and multilayer elements). PZT thin films are used for force sensors, accelerometers, gyroscope motors, micropumps [2].

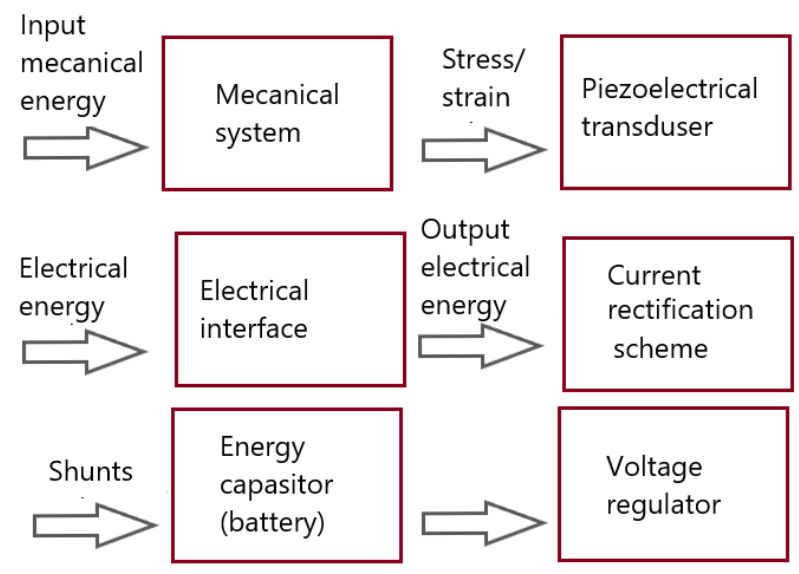

Fig. 1. Structure of energy harvesting devices

The connection between the piezoelectric elements is provided by a shunt chain [3]. In Fig. 1 it is presented as a rectification scheme. In the case of passive damping, due to the piezoelectric effect, part of the mechanical energy of the oscillations of the structure is converted 
into electrical and is removed or collected by means of a shunt circuit.

For active damping, actuators oscillating in antiphase with undesired design frequencies are also introduced into the circuit. The mode of operation of the actuators is determined from the data obtained from sensors that read and transmit to the controller the existing electromechanical or acoustic state of the element. Resonant shunt circuits are able to adjust to the frequency to be damped, due to the presence of an inductor and a resistor. The piezoelectric element in the electrical circuit works as a capacitor.

The obtained electricity is stored in a capacitor, supercapacitor or battery (energy storage on Fig. 2). Capacitors are used for possible large voltage spikes. Batteries are used when the device requires a steady flow of energy. Supercapacitors have virtually unlimited charge-discharge cycles, but are much less accessible than capacitors.
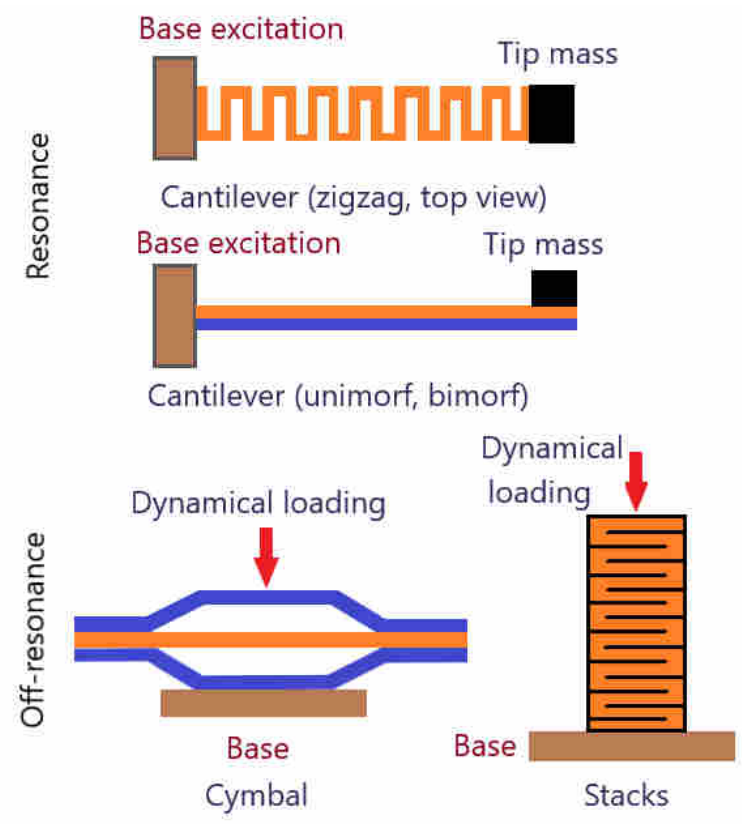

Fig. 2. Piezoelectrical elements for harvesting of energy

\section{TYPICAL PIEZOELEMENTS FOR HAR- VESTING OF ENERGY}

The cantilever rod is one of the most widely used forms of piezoelectric energy harvesters [4], especially for mechanical energy collection from vibrations, because of the piezoelec- tric element during vibration can get significant deformation. The manufacture of piezoelectric consoles is relatively simple and inexpensive. The main bend frequency of the console is much lower than other modes of vibration of the piezoelectric element. Most developed piezoelectric devices use a unimorph (one layer of piezoelectric material attached to a non-piezoelectric layer) or a bimorph (two layers of piezoelectric material attached to a non-piezoelectric layer). The bimorph structure doubles the energy given off, so it is used more often than the unimorph one. To adjust the resonant frequency of the console, an additional mass is attached to the free end.

Non-resonant energy transducers are usually in the form of a plate or a multilayer piezoelectric element (stacks) [5]. The structure of the transducers in the form of plates enhances the mechanical impact used to improve the output power of energy harvesting.

In stack architecture, piezoelectric materials are used in the mode of longitudinal oscillations, which have a higher conversion factor than the transverse mode. Since the first natural frequency of piezoelectric stacks usually exceeds $1 \mathrm{kHz}$, while the natural oscillations of the structure usually occur in the range of $10 \mathrm{~Hz}-100 \mathrm{~Hz}$, such piezoelectric elements are used out of resonance. Plates and stacks have low vibration sensitivity with low amplitude, but can withstand much higher mechanical loads (especially stacks) than cantilever energy collectors.

Matching elastic or viscoelastic layers are used in the stacks to match the resonant frequencies of the transducer with the oscillating frequencies of the structure [6]. To determine the real oscillations amplitudes of elements at resonant frequencies, energy dissipation is taken into account [7].

\section{MATHEMATICAL EQUATIONS}

Full system of piezoceramic body vibrations includes equation of continuous medium motion $\sigma_{i j, j}=\rho \ddot{u}_{i}$; quasi-static approximation of Maxwell's equations $D_{i, i}=0, E_{i}=-\varphi_{, j}$; piezoeffect physical relations in form $\sigma_{i j}=c_{i j k l}^{E} \varepsilon_{k l}-e_{k i j} E_{k}, \quad D_{i}=e_{i k l} \varepsilon_{k l}+\varepsilon_{i k}^{S} E_{k}$, or in 
equivalent form $\varepsilon_{i j}=s_{i j k l}^{E} \varepsilon_{k l}+d_{k i j} E_{k}, D_{i}=d_{i k l} \sigma_{k l}+\varepsilon_{i k}^{T} E_{k} ; \quad$ and geometric Cauchy relations $\varepsilon_{i j}=\left(u_{i, j}+u_{j, i}\right) / 2$, which are written using the notation accepted in tensor algebra. In this relations $\sigma_{i j}, \varepsilon_{i j}$ - components of tensors of mechanical stresses and strains; $u_{i}, D_{i}, E_{i}$ components of vectors of mechanical displacements, electrical induction and electric field strength; $\varphi$ - electrical potential; $\rho$ medium density; $\quad c_{i j k l}^{E}\left(s_{i j k l}^{E}\right), \quad e_{k i j}\left(d_{k i j}\right)$, $\varepsilon_{i k}^{S}\left(\varepsilon_{i k}^{T}\right)$ - elastic, piezoelectric and dielectric constants for piezoceramic. For elastic inductive elements of system there are used the same relations with zero piezoelectrical constants. Differential equations are closed with boundary conditions. At mechanical loading on open electrodes appears difference in potentials, what can be found from condition $\int_{\Omega_{l}} \dot{D}_{i} n_{i} d \Omega=0$. For bodies of simple geometry (cantilever beam or round disk) the problem can be reduced to one-dimensional equations, what can be simply solved.

\section{CONCLUSIONS AND RECOMMENDA- TIONS}

Energy harvesting using piezoelectric transducers is a promising and rapidly evolving area in engineering. The application of the proposed technologies allows to convert unnecessary oscillations into electrical energy and accumulate it for further autonomous operation of the device. The geometry of typical piezoelectric elements used in energy collection is quite simple and allows to reduce the problem to one-dimensional equations that can be solved analytically or by simple numerical means.

The reaction of the piezoelectric element on mechanical perturbation in the nonstationary mode requires multimode analysis. But perturbations propagating in elements in other directions can cause undesirable effects at certain frequencies.

Therefore, for a clear understanding of the operating conditions of the device, it is necessary to conduct additional analysis with threedimensional theory using numerical methods, taking into account the influence of the environment and matching viscoelastic layers.

Keywords: energy harvesting, piezoceramic sensor, transduction of energy, accumulating of energy, autonomous devices, resonance and offresonance modes.

\section{REFERENCES}

1. Dongna Shen (2009). Piezoelectric energy harvesting devices for low frequency vibration applications. Dissertation for the Degree of Doctor of Philosophy. Auburn, Alabama.

2. N. X. Yan, A. A. Basari and N. A. A. Nawir (2018) Piezoelectric ceramic for energy harvesting system: a review. ARPN Journal of Engineering and Applied Sciences, 13 (22), 8755-8775.

3. В.П. Матвеенко, Е.П, Клигман, М.А. Юрлов, Н.А, Юрлова (2012). Моделирование и оптимизация динамических характеристик smartструктур с пьезоматериалами. Физическая мезомеханика. 15 (1), 75-85.

4. https://www.americanpiezo.com/blog/ piezoelectric-energy-harvesting

5. N. Sezer, M. Koç (2021). A comprehensive review on the state-of-the-art of piezoelectric energy harvesting. Nano Energy, 80, 105567.

6. Grigoryeva, L.O. (2020) Transient responses in Piezoceramic Multilayer Actuators Taking into Account External Viscoelastic Layers. Опір матеріалів і теорія споруд. Strength of Materials and Theory of Structures. 105, 255-266.

7. Григор'єва Л. О., Безверхий О. І. (2020) Резонансні коливання п'єзокерамічних циліндрів 3 врахуванням дисипації енергії. Проблеми обчислювальної механіки та міцності конструкцій, 31, 44-54. 